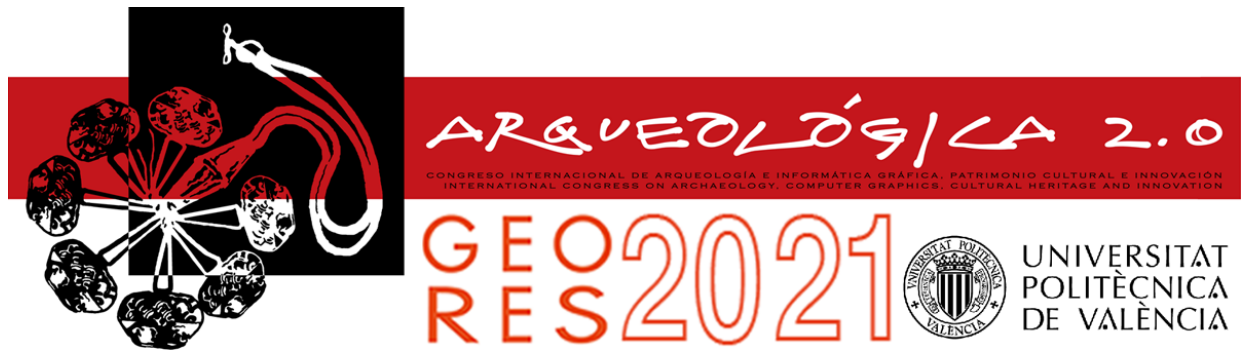

Proceedings of the joint international event $9^{\text {th }}$ ARQUEOLÓGICA

$2.0 \& 3^{\text {rd }}$ GEORES

Valencia (Spain).

26-28 April 2021

\title{
BIM DESIGN LEAD FOR RESTORATION OF SHIPWRECK MUSEUM IN KYRENIA CASTLE IN CYPRUS
}

\author{
Carlo Biagini", Francesco Capparelli, Giorgio Verdiani \\ Department of Architecture, University of Florence, Via della Mattonaia 14, 50121 Firenze, Italy. carlo.biagini@unifi.it; \\ francesco.capparelli94@gmail.com; giorgio.verdiani@unifi.it
}

\begin{abstract}
:
The paper deals with the application of Building Information Modelling (BIM) to the documentation and preservation of Archaeological Heritage, illustrating the implementation process to a case study. The work process started from the historical analysis together with the geometric capturing of the built morphology. A 3D model was created by combining laser scans and a digital photogrammetric survey. To make all 3D data sets interoperable, it was developed a BIM project execution plan focused on the restoration of Shipwreck Museum in the Kyrenia Castle in Cyprus. The HBIM approach not only allows to represent of the existing historic fabric with an effective visualization but also to lead a complex analysis of designed interventions in various scenarios. BIM objects were modelled and managed parametrically for a synthetic definition of the individual elements. All the additional information besides the geometrical data were stored into the HBIM able to document the maintenance and to help the future works. It will be illustrated the procedure and the methodology by presenting the outcomes of the research.
\end{abstract}

Keywords: Kyrenia Castle, H-BIM for archaeology, digital survey, Cyprus, fortifications, built heritage

\section{Introduction}

The collection of data and information on the historicalarchitectural heritage, aimed at producing accurate and complete documentation in the context of diagnosis, restoration, digital integration, design, and museum enhancement, has recently become possible even with a rather reduced available budget (Banti, 2020). Digital detection solutions based on latest generation instruments, which use active as well as passive systems, today offer versatile opportunities for interventions on historical architecture, without worrying about the size of the building: identification of objectives and correct planning of activities are essential to proceed effectively and continuously in a digital survey operation.

The network of fortifications across the Mediterranean, with its specific balance between "heritage buildings at risk" and "high-quality landscapes/historical landmarks" (Verdiani, 2016), is one of the most interesting themes that may benefit from such an approach. In the case of Kyrenia Castle on the island of Cyprus (Fig. 1), a combination of terrestrial and aerial photogrammetry on the one hand and terrestrial lasergrammetry, on the other hand, took place in 2018 at an academic workshop organized by Girne American University with the participation of a unit from the Department of Architecture, University of Florence (Camiz, Verdiani, \& Ceylanli, 2018). Kyrenia Castle is a large medieval fortification laid out in an almost square plan with sides of about 150 meters long and walls of up to about 30 meters high. On the occasion of the laboratory, opened for a week in May 2018, the first (partial) digital model of this great heritage building was produced. Following the best practices of a digital survey, the operative group, together with the management unit of the castle museum, performed a detailed investigation, from the study of the morphology of the castle to its stratigraphy and from the restoration problems of the museum to the exhibition aspects, including the production of multimedia content for the general and/or the more technical public. Such an accurate data set is the ideal basis for developing a more "evolved" digital twin of the castle, or at least of some of its "strategic" parts, such as the museum complex. Although it welcomes one of the fundamental discoveries of underwater archaeology, such as the Kyrenia Shipwreck (Steffy, 1985), the need for an overall redesign in line with contemporary museum strategies is strongly felt. The creation of a parametric model of the museum area developed in the Autodesk Revit $^{\odot}$ environment was thus an opportunity to experiment with an H-BIM approach in the study of a relevant example of a historical-archaeological heritage building (Capparelli, 2019) (Fig. 2).

\section{BIM design lead for restoration}

The digitization of building information processes has long since extended to the cultural heritage sector too, for which the use of Building Information Modelling

`Corresponding Author: Carlo Biagini, carlo.biagini@unifi.it 
technologies has opened up new scenarios in the management of historical-architectural heritage (Murphy, McGovern, \& Pavia, 2013). However, the transfer of information modelling approaches effectively tested in new constructions raises issues that are still not completely resolved in the context of existing buildings (Antonopoulou, 2017).

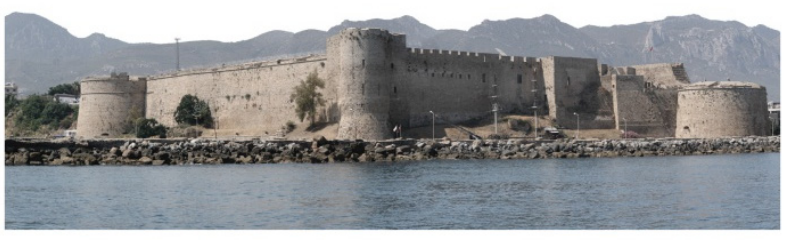

Figure 1: A view of Kyrenia Castle in Cyprus.
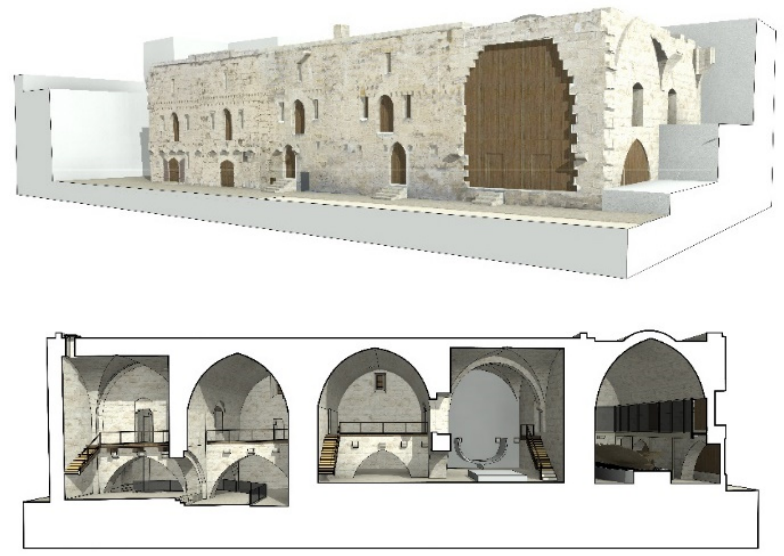

Figure 2: H-BIM model of the Kyrenia Shipwreck Museum.

On the one hand, the advances obtained in recent years by Geomatics in terms of portability, ease of use, speed and precision of measuring instruments, have not been matched by an adequate improvement in the automation tools for the implementation of information models. Indeed, the "Existing condition modelling" processes are highly asymmetrical in scan-to-BIM procedures between the phase of massive acquisition of geo-spatial data and the creation of parametric models (Quattrini, Clini, Nespeca, \& Ruggeri, 2016). On the other hand, in a broader perspective of an asset life cycle, the information management of historic buildings requires a more comprehensive redefinition of delivery and operational phases, regulated not only by design information requirements but by a specific conservation philosophy (Biagini, Donato, Capone, \& Facchini, 2016).

In particular, the information management of the historical heritage must be able to hold new information classes related to the asset management strategies of the employer (owner/manager), and other important items such as shared cultural values and recognized meanings in built heritage; conservation criteria informed to the most advanced theories and restoration techniques; needs of architectural survey and instrumental testing campaigns required for the various specialist investigations; identification of rehabilitation, functional adaptation, maintenance and conservation interventions (Brumana et al., 2017).

On the first issue, there are now many studies and research, which have tried to propose information management procedures on specific objectives; they were aimed at implementing parametric models of built heritage, focusing mainly on the levels of accuracy and geometric detail achievable in the modelling of historical building elements, starting from an assigned granularity of the captured geometric data (Biagini \& Donato, 2014).

However, the production of "BIM-ready" models, without a clear identification of objectives of use, always constitutes a partial response to the information requirements of asset management set by an employer, and often the premise of further heavy processing phases. That is especially in cases where the morphological complexity of the historical building requires advanced customization of the parametric objects, abandoning the ordinary modelling of the software's native objects of BIM authoring (Volk, Stengel, \& Schultmann, 2014), hybrid solutions, in which geospatial data sets coexist with parametric objects, limiting the modelling to the new conservationmaintenance-restoration interventions, certainly represent interesting alternatives at low cost and quick to implement (Brookes, 2017). However, they strongly reduce the potential use of the BIM model. The need to identify an information vehicle, able to integrate the different dimensions of the building project (graphics, documents, multimedia), shifts attention to the management of the database underlying the parametric model, and to the multiplicity of data that the historical built heritage has inherited from a more or less recent past (archival documents, reliefs, photos, surveys, etc.). This is a problem that configures a new idea of information model no longer virtualized in the simple digital transposition of the building semantics but moreover identified with the same data-sharing environment (CDE common data environment), which can be interrogated through data-mining procedures.

This recent proposal is working in this perspective, aimed to change the information development standard of models and objects in the restoration setting (UNI 113374,2017 ), which provides for overcoming the rigid double articulation of the current Levels Of Development (LOD) in the two items, Level Of Geometry (LOG) and Level Of Information (LOI), towards a more complex articulation of graphic models and document systems, which is expressed through a new "Level Of Information Need" (LOIN) (Brumana, Banfi, Cantini, Previtali, \& Della Torre, 2019).

\section{Modelling methodology and solutions}

Some techniques of parametric modelling applied to the historical heritage have been experimented with in the survey of the Kyrenia Castle, affecting one of the most significant parts of the fortified complex, the Shipwreck Museum (Fig. 3). With a BIM model, it was carried out an effective tool for the evaluation of design choices aimed at the enhancement of the museum rooms, which are devoid of a uniform layout and adequate lighting technology, despite the presence of a naval archaeological find of considerable value dated between IV and III sec. B.C. 


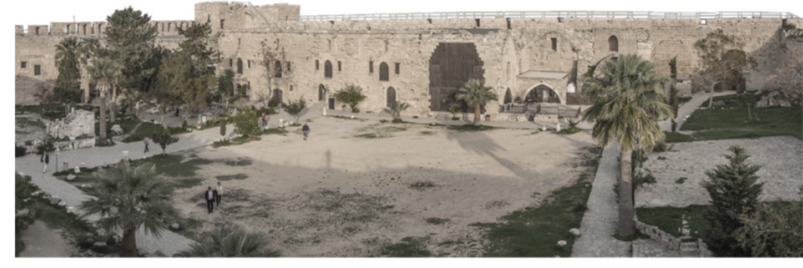

Figure 3: A view of the central courtyard and Shipwrek Museum

The Kyrenia Castle represents three distinct periods of architectural development, as the techniques of warfare advanced from bows and arrows to the invention of gunpowder and cannons (Camiz, Khalil, Cansu Demir, \& Nafa, 2016). It is an excellent example of tracing the evolution of medieval military castles in that area with a specific reference to other European models from the same period (Cathcart King, 2019). The periods of the fortifications are: First phase, Byzantine (330-1192); second phase, Lusignan (1192-1472); third phase, Venetian (1472-1570). The "Kyrenia shipwreck", the common name used to indicate the important finding of a ship from the IVth century BC in the waters in front of Kyrenia (Katzev, 1981), also supports the idea about the presence of an important port town. However, there is no evidence of a Roman military castle. The hull remains of the ship are preserved inside the castle museum (Katzev, 2008). The castle has round towers, solid curtain walls, gun ports and ramparts, all typical elements of the Venetian military architecture. Inside there are wellpreserved cells, accommodations, and water cisterns to be used in case of a siege. The drawbridge over a moat was the only way to access the castle. The North East tower of the Kyrenia castle is a Lusignan "horseshoeshaped" tower with angled footing and loopholes for firing longbows. The Lusignan Donjon is today still partially visible. The Kyrenia town was a fortified town with its towers acting as part of the castle fortification which was further enhanced by the Venetians and went out of use during the Ottoman period (Petre, 2010). In facts, the castle did not resist to the Ottoman expansion, in 1571, the Kyrenia castle surrendered without firing a single shot.

\subsection{Digital Survey of the Castle}

All the digital survey operations were done during the workshop in Kyrenia in May 2018. The 3d laser scanner in use for this survey was a Zöller-Froelich Z+F Imager $5006 \mathrm{~h}$ a phase-shift unit capable of gathering points at a distance up to 80 metres with an accuracy of about two millimetres on a standard reflective material (Fig. 4). For all the scans it was preferred to use settings with a density of points in "middle" mode (in this survey work this setting created point clouds defined up to nine million points) or "high" mode (this setting allow the creation of point clouds up to 19 million points) and with an accuracy mostly set to "high" for the scans done in full light and open spaces (with redundancy of five measurements for each point) and "medium" in interiors and low light situations (with redundancy of three measurements for each point). In this way, each scan station asked about three to six minutes, plus the positioning times. Because of the high level of details and the possibility to have articulated shapes with well recognizable characteristics, the use of targets for supporting the alignment procedures was reduced to a minimal, using mostly classic "black and white" paper checkerboard targets in strategic situations. A logic of "reduction" of the occlusion spaces (Bini, \& Bertocci, 2012) and of "support" to the following automatisms in point cloud alignments (Pomerleau, Colas, \& Siegwart, 2015), guided the planning of the survey strategy. In this way, it was possible to have short post-processing times and fully descriptive results. The lasergrammetry survey covered the part of the castle from the entrance up to the central court along the main passage and from there to the museum areas, the inner part of the northern tower, all the higher passages and the area of the Church. In five days, 257 scan stations were completed, gathering about 2.5 billion points.

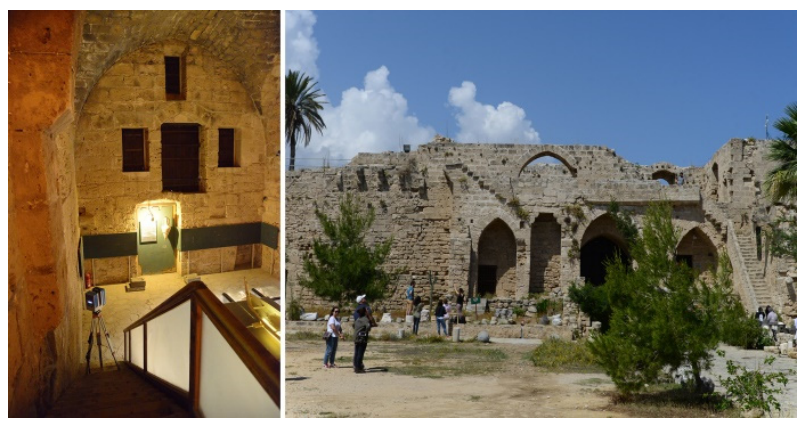

Figure 4: The 3D Laser Scanner Unit inside the Museum Area. Ground view of the central courtyard towards East.

The first phase of a BIM planning process involves the identification of BIM Uses. In this case, an attempt has been made to provide an informative basis for the restoration and conservation, using the "modelling of existing conditions". Based on the construction characteristics of the manufacture, particular attention has been paid to the collection of data and information relating to walls and masonry surfaces, which were then implemented in the model. Besides, it was necessary to conduct in-depth studies of the various archival and bibliographical sources available for the modelling of the historical sequence of the construction phases.

\subsection{Geometric modelling}

The geospatial data-set acquisition of the building was developed using the base reference coming from the digital survey campaign, exploiting the over 250 collected scans produced with the Zoller+Fröhlich Imager 5006h 3D laser scanner, the 1.900 aerial shots taken by the UAV unit (Barba, Barbarella, Di Benedetto, Fiani, \& Limongiello, 2019) and the over 30.000 terrestrial photographs taken using a set of high-resolution digital cameras. The creation of the BIM model was brought on within Autodesk $\operatorname{Revit}^{\odot}$. This was subjected to a preliminary process of decimating and cleaning of the redundant data, segmenting the global point cloud into parts to avoid excessive slowdowns in the workflow, before importing the point cloud in the BIM authoring software. These operations were carried out through Autodesk Recap@, fully interoperable with Autodesk Revit@ (Figs. 5 \& 6). In the modelling of parametric objects, it was possible to experience the potential of Revit $^{\odot}$ in the creation of complex shapes, such as those of the walls and vaults of the Shipwreck Museum rooms. The level of accuracy of a BIM model depends significantly on the degree of simplification applied to the modelling of objects, which may in some cases not be 
commensurate with the needs of the subsequent design phases of the restoration (Eastman, Teicholz, Sacks, \& Liston, 2011).

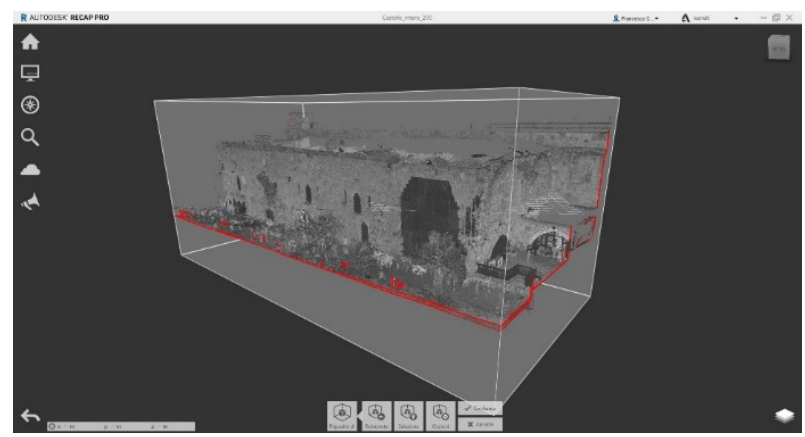

Figure 5: Cut part of the point cloud in Autodesk Recap ${ }^{\odot}$.

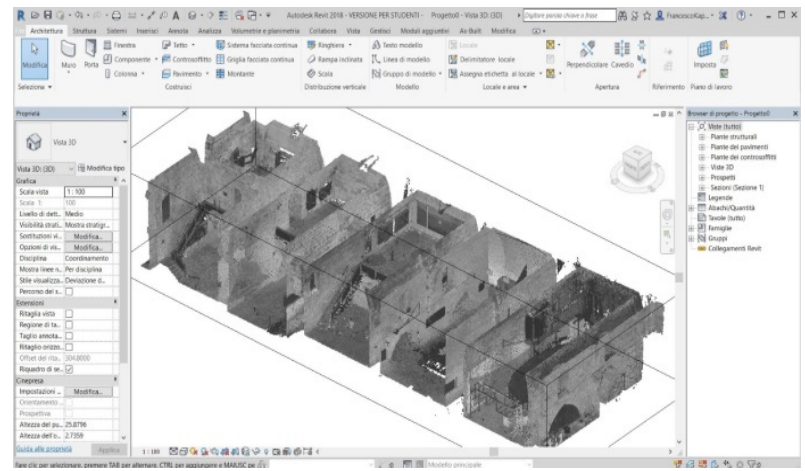

Figure 6: Point cloud imported in Revit ${ }^{\odot}$.

For this reason, it has been made wide use of objects modelled "in-place", having to renounce to the fastest automatic procedures of the software that is to the use of "system families". Irregular shapes and non-standard geometries can be created through the local modelling tools and inserted in specific categories, to allow management through the definition of schedules. However, they do not enjoy the parametric properties of standard objects. So, each wall was modelled considering it individually, thus being able to obtain a model more adherent to the point cloud and close to the real object. A similar modelling process was used in the creation of the vaults, all characterized by a high irregularity (Fig. 7). For this "adaptive metric families" were used: "adaptive" points have been set to be positioned manually within the model in addition to the usual control parameters, allowing to match a regular basic geometry to a specific conformation.

The doors and the windows modelling were made in two different ways according to the complexity (Fig.8):

a) Through the creation of parametric families using the dimensional indications obtained from the point cloud and quoting plant, façades, and sections for each type.

b) Through the creation of "in-place" geometries, in cases where the geometry and/or the wall shape did not allow the insertion "clean" of a family, it was preferred to proceed with in-place modelling of subtraction solids to be applied on the geometry of the masonry.
In this work, it was also experimented the Revit plug-in FARO As-built, by modelling some components of the museum rooms. The plugin has advantageous modelling capabilities, which allow you to maintain a remarkable correspondence with the point cloud. However, sometimes the results have not been satisfactory, such as in the modelling of masonry with inclined surfaces relative to the vertical plane.
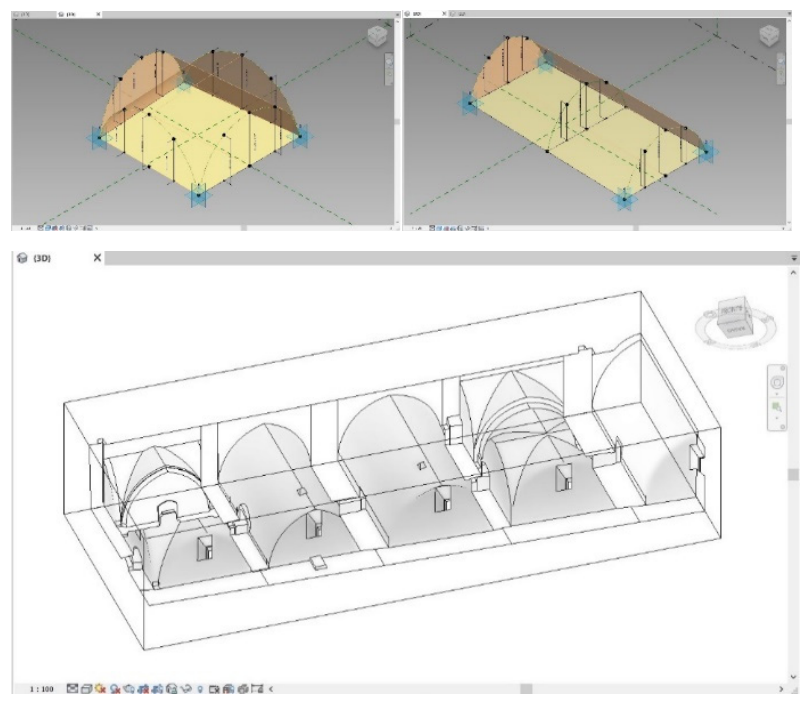

Figure 7: The adaptive vaults imported into the model.

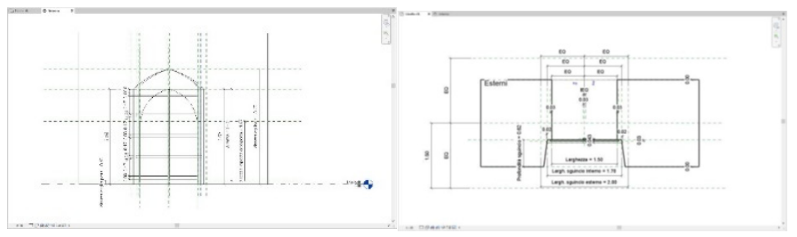

Figure 8: Example of a door parametrically modelled.

The transformation of the Kyrenia ship's point cloud into a polygonal network (mesh) took very complex modelling (Fig. 9). As a first step, the point cloud was imported in Raindrop Geomagic Studio, using this software to "clean up" the dataset and then turn it into a mesh. Before importing it in Revit, a simplification of the mesh was needed. It was done using the function named "mesh Doctor" in Geomagic Studio. This allowed to reduce and optimize the triangles avoiding possible slowing down in the following processing. Then the mesh has been imported into Autocad, its scale was checked back according to the original measurements and then export it into DXF file format to make it compliant with Revit. The Kyrenia ship's mesh has been imported in the Revit model as an "in-place" mass, allowing to create and insert new parameters within it, for example, identification code, description, location, historical phase, materials, references, and conservation status.

A specific task allowed to verify the accuracy of the model concerning the points cloud after its completion. There are inevitably differences between the point cloud and the BIM model because it remains an approximation of the real object. Also, in this case, FARO As-built was used to quantitatively verify this correspondence, capable of measuring the deviation of the surfaces/mesh of the model concerning the point cloud. The plugin automatically aligns the $3 \mathrm{D}$ model and the point cloud 
according to specific cutting planes. It has been found that the mean deviation error is less than $3-4 \mathrm{~cm}$, which is more than acceptable about the geometric characteristics of the artefact analyzed.

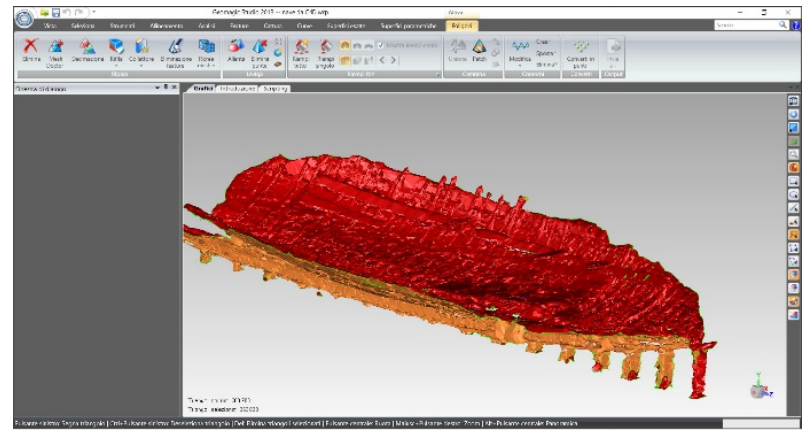

Figure 9: The Kyrenia ship mesh model converted from the point cloud.

\subsection{Information modelling}

The information collecting activity due to implement in the HBIM model is a very complex phase of its creation process and not yet fully evaluated in its implications. It is a matter of developing not only in-depth research of the documentary direct and indirect sources available on the building, but of proceeding with a careful selection based on the type of collected document, which can be computing structured or not, and fixed on digital support or not. For example, in the digital transformation of original paper documents, the data resolution requirements must be carefully evaluated to avoid unnecessary waste of resources and management difficulties. Therefore, it is fundamental the information management strategy in the various phases of the life asset cycle, which is to be implemented.

Each component and space of the model has indeed a predefined set of alpha-numeric parameters, which can be suitably implemented to collect all the information related to the specific objectives of the model and the expected BIM uses. Furthermore, any type of external digital file can be associated with the model through appropriate links to its elements: product specifications, user and maintenance manuals, multimedia documents, etc. The linked files can also be used through external applications. The information modelling phase of the Kyrenia Shipwreck Museum involved the insertion of alpha-numerical information relating to materials, decay, and construction techniques of the different architectural components within the 3D geometries. In particular, the following sets of information contents have been identified:

1) Cadastral documentation and historic and existing drawings of the building.

2) Geometric survey of the building.

3) Thematic survey on the conditions of materials and structures decay.

4) Investigation of the historical characteristics of the building components.

5) Details of construction techniques.

The information entered in the model can be managed, filtered, and appropriately selected through shared parameters, and collected in schedules of homogeneous elements, referred to as the component's families. Each element was associated with an alphanumeric identification code, a name, a brief description, the historical phase of reference, the construction technique, and the constituent material.

The information management relating to the material decay of the wall faces is carried out by viewing the photoplanes suitably geo-referenced on the surface of the corresponding wall component (Fig. 10). Through external links inserted in some shared parameters, it is possible to recall the decay sheets associated with that specific wall (Fig. 11). After completing the model about the existing condition of the Kyrenia Shipwreck Museum and a careful evaluation of the current problems of the museum complex, a project has been proposed to redevelop and enhance the exhibition rooms, exploiting parametric modelling tools to manage the design phase and to plan the stages of the project interventions.

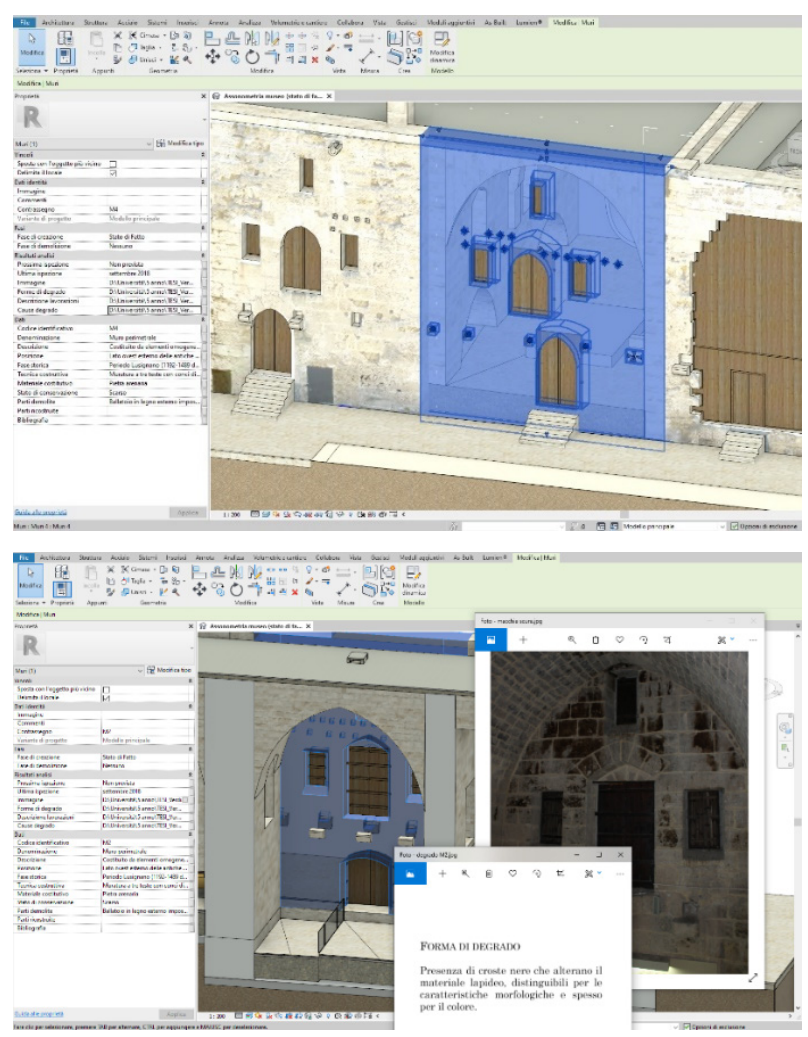

Figure 10: Examples of parameters inserted in walls.

\section{Outcomes}

At the end of the BIM modelling, a database was obtained containing all the information relating to the historical asset to document its state of conservation, making it a potential tool for managing cultural heritage and a resource for studies and future research.

The model also allows extrapolating schedules in a simple and fast way through a filtering system made available by the $\mathrm{Revit}^{\odot}$ software, based on the family's classes and the parameters contained in the single objects.

The following identification fields have been associated with each parametric object: identification code, naming, description, position, historical phase, construction technique, constituent material, state of conservation, demolished parts, reconstructed parts, and the bibliographic references of the single component. Other 
included fields concern the survey results for the restoration: next and last inspection, photos, forms of decay, decay causes, description of works. All of these fields can be filled in within Revit $^{\odot}$, automatically appearing within the schedules, or associated with external links, which refer to JPG, PDF or XLSX documents achieved in the data-sharing environment (CDE). In this way, it will be possible for the museum manager himself to update the information stored in the model every time the building is carried out for maintenance /conservation /restoration activities (Ceylanlı, Özen, Çiçek, \& Arslan, 2019). This approach will make it possible to have complete and reliable information within a few years (technical information, maintenance, installation date, etc.) to guarantee efficient operational management of the asset (Günçe \& Misirlisoy, 2014) (Fig. 12).

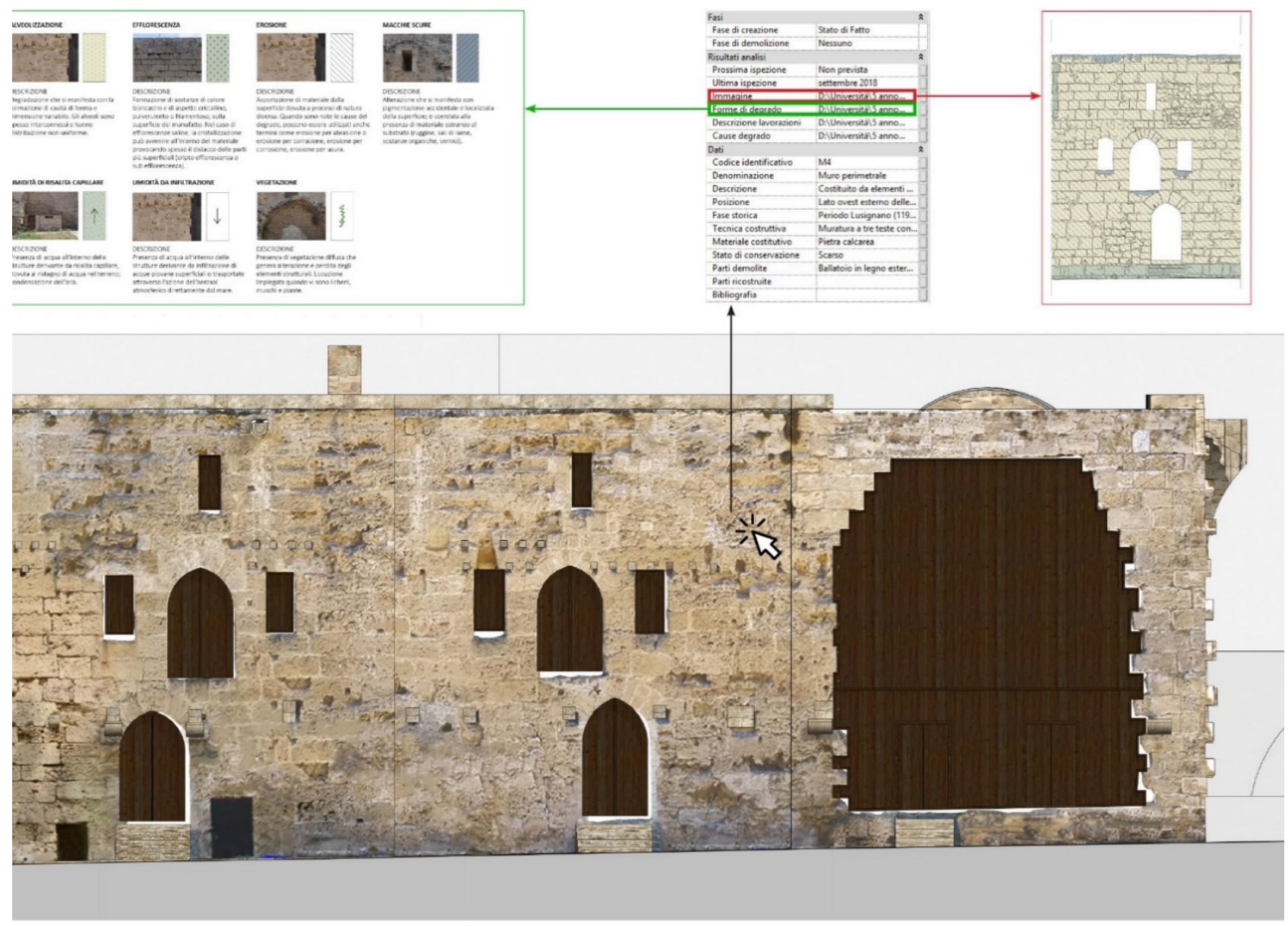

Figure 11: Information management of the material decay.

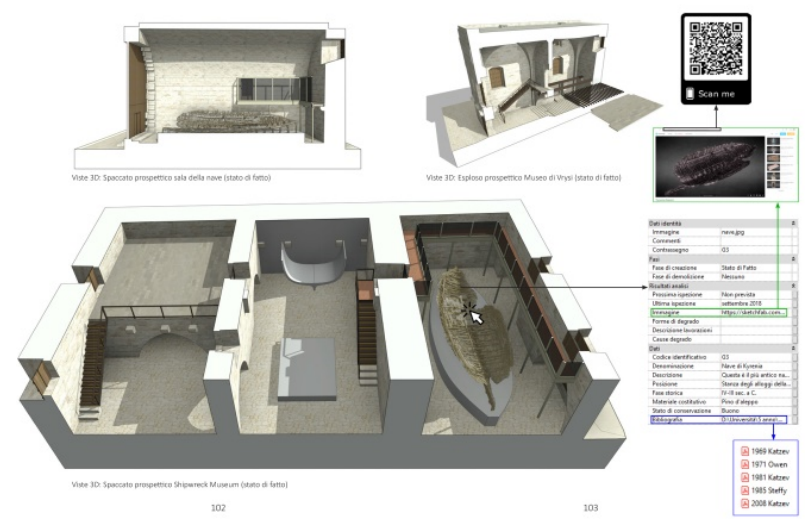

Figure 12: Information management of research references.

\section{Conclusions}

The present study has highlighted the potential and limits of BIM applications to historical built heritage. There are still many difficulties to overcome in reproducing an architectural object through parametric modelling, which moves away from regular geometric patterns. In the archaeological field, this problem is even more relevant, having to abandon any automated modelling technique and proceed to customized production of the parametric objects. Although some Revit ${ }^{\odot}$ plugins exist on the market bringing simplifications in the modelling of components based on point cloud datasets, they are not yet completely available in meeting all the modelling needs of such a complex artefact like the Kyrenia Castle. The complete implementation of similar HBIM models would require the development of specific libraries created with adaptive parametric objects, capable of conforming to the conditions of uniqueness that characterize the corresponding real objects.

The achieved results show that H-BIM modelling is progressively overcoming the initial critical issues related to the standardized creation of objects and that the solutions available for their customization, although still not completely satisfactory, already suggest probable advances in terms of efficiency and reliability. The final BIM model included the production of the analysis 
drawings of the historical building and the project of the museum restoration. $2 \mathrm{D}$ and $3 \mathrm{D}$ views are also extracted from the model (axonometry, plans, sections, elevations, and details) and displayed in an appropriately chosen graphic style with notes, photos, and details (Fig. 13).

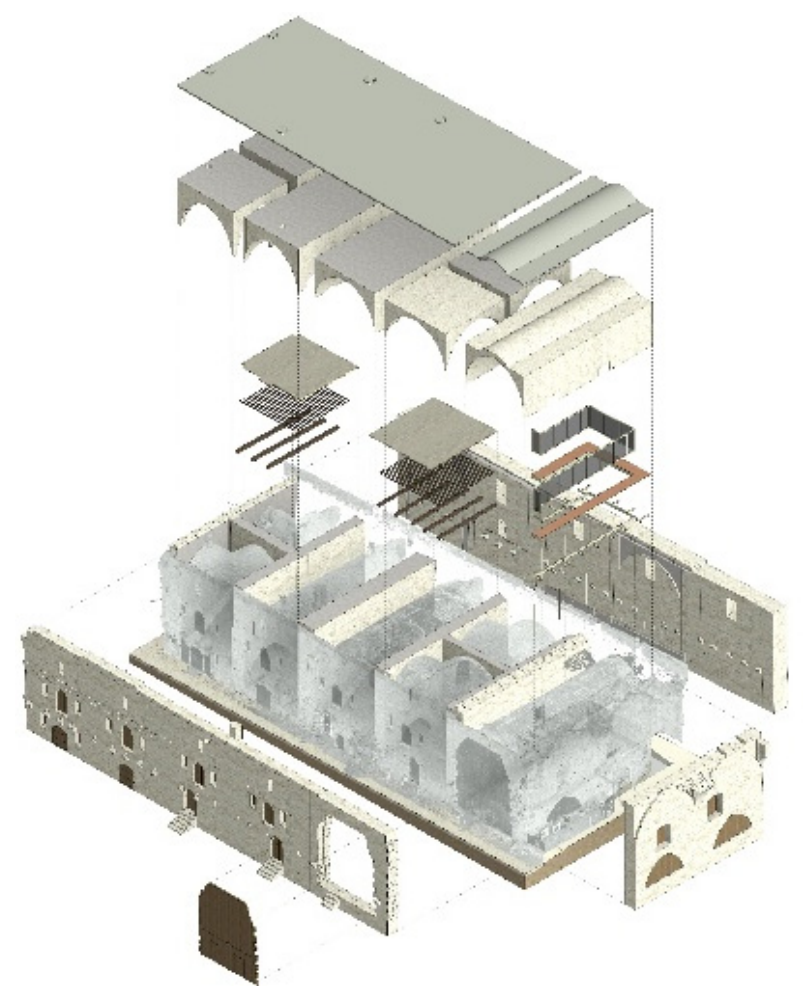

\section{Acknowledgements}

The study presented here is based on the survey produced during the workshop "Reading and Designing the Kyrenia Castle", 6th-13th May 2018, organized by the Girne American University (Department of Interior Architecture), with the Department of Architecture of the University of Florence and the Department of Interior Architecture of the Özyeğin University, Istanbul. The authors would like to thank all the members of the scientific committee and in particular Alessandro Camiz, Stefano Bertocci, Zeynep Ceylanli, Giovanni Carbonara, Roberto Secchi, Kutsal Öztürk, Orhan Hacıhasanoğlu, Carlo Bianchini and Daniela Esposito, for their collaborative support. Within the organizing committee, a special acknowledgement must be given to Pembe Özen and the entire Department of Antiquities and Museums for constant participation.

Figure 13: Exploded Isometric view of the 3D model.

\section{References}

Antonopoulou, S. (2017). BIM for Heritage: Developing a Historic Building Information Model. Swindon. Historic England.

Banti, F. (2020). HBIM, 3D drawing and virtual reality for archaeological sites and ancient ruins. Virtual Archaeology Review, 11(23), 16-33.

Barba, S., Barbarella, M., Di Benedetto, A., Fiani, M., \& Limongiello, M. (2019). Quality assessment of UAV photogrammetric archaeological survey. International Archives of the Photogrammetry, Remote Sensing \& Spatial Information Sciences, XLII-2/W9, 93-100.

Biagini, C., \& Donato, V. (2014). Building Object Models (BOMS) for the documentation of Historical Building Heritage. In proceedings of the $V$ Congreso Egrafia, 142-9. Rosario, Argentina.

Biagini, C., Capone, P., Donato, V., \& Facchini, N. (2016). Towards the BIM implementation for historical building restoration site. In Automation in Construction, Elsevier, 71, 74-86.

Bini, M., \& Bertocci, S. (2012). Manuale di rilievo architettonico e urbano, CittàStudi, Torino, Italia.

Brookes, C. (2017). The Application of Buiiding Information Modelling (BIM) within a Heritage Science Context. Ramboll. Historic England.

Brumana, R., Banfi, F., Cantini L., Previtali, M., \& Della Torre, S. (2019). HBIM Level of Detail-Geometry-Accuracy and Survey Analysis for Architectural Preservation. In Proceedings of the Geores conference 2019, 293-99, Milan, Italy.

Brumana, R., Della Torre, S., Oreni, D., Previtali, D., Cantini, L., Barazzetti, L., Franchi, L., \& Banfi A. (2017). HBIM challenge among the paradigm of complexity, tools and preservation: the basilica di Collemaggio 8 years after the earthquake (L'Aquila). In proceedings of the XXVI CIPA Symposium, 97-104. Ottawa, Canada.

Camiz, A., Verdiani, G., \& Ceylanli, Z. (2018). International workshop: reading and designing the Kyrenia castle. In Symposium of Representation Scientific Area for Development of Multidisciplinary International Programs, 264-298, Florence, Italy.

Camiz, A., Khalil, S., Cansu, Demir, S., \& Nafa, H. (2016). The Venetian defense of the Mediterranean: the Kyrenia Castle, Cyprus (1540-1544). In Verdiani G. (Eds.) Defensive architecture of the Mediterranean. XV to XVIII centuries, 3, 
DIDApress. 371-8. Florence, Italy.

Ceylanlı, Z., Özen, P., Çiçek, E., \& Arslan, P. (2019). Evolving from castle to virtual space: the case of Kyrenia Shipwreck Museum, in Proceedings of the CHNTNH Conference, Museen der Stadt Wien, Stadtarchäologie, Vienna, Austria.

Capparelli, F. (2019). BIM solutions for the architecture and archaeology: the case of the Kyrenia Shipwreck Museum, a 25 centuries long path. (Master thesis) University of Florence, Italy.

Cathcart King, D. J. (2019). The Castle in England and Wales: an Interpretive History. Routledge, United Kingdom.

Eastman, C., Teicholz, P., Sacks, R., \& Liston, K. (2011). BIM Handbook. A Guide to Building Information Modelling for Owners, Managers, Designers, Engineers and Contractors. Hoboken, New Jersey, Wiley\&Sons Inc.

Günçe, K., \& Mısırlısoy, D., (2014). Adaptive reuse of military establishments as museums: conservation vs. museography, in *WITTransactions on The Built Environment*, 143, WIT Press, 125-132.

Katzev, M. L. (1981). The Reconstruction of the Kyrenia Ship, 1972-1975. In National Geographic Society Research Reports, 13, 315-28, Washington D.C..

Katzev, S. (2008). The Kyrenia Ship: Her Recent Journey. In Near Eastern Archaeology, 71(1/2), 76-81, The American Schools of Oriental Research.

Steffy, J.R. (1985). The Kyrenia Ship: An Interim Report on Its Hull Construction. In American Journal of Archaeology, 89(1), 71-101, Archaeological Institute of America.

Murphy, M., McGovern, E., \& Pavia, S. (2013). Historic building information modelling-Adding intelligence to laser and image based surveys of European classical architecture. In ISPRS Journal of Photogrammetry and Remote Sensing, 76, 89-102.

Petre, J. (2010). Crusader Castles of Cyprus, the fortifications of Cyprus under the Lusignans: 1191-1489. Microform Edition ProQuest LLC, 789 East Eisenhower Parkway.

Pomerleau, F., Colas, F., \& Siegwart, R. (2015). A Review of Point Cloud Registration Algorithms for Mobile Robotics. In Foundations and Trends $₫$ in Robotics, 4(1), pp 1-104, Now Publisher, USA.

Quattrini, R., Clini, P., Nespeca, R., \& Ruggeri, L. (2016). Measurement and Historical Information Building: chalenges and opportunities in the representation of semantically structured 3D content. In DisegnareCon, 9(16), 1-11.

UNI 11337-4 (2017). Construction and civil engineering works - Digital management of information processes of construction. Level of development (LOD).

Verdiani, G. (Ed.) (2016). Defensive Architecture of the Mediterranean. XV to XVIII centuries, 3, DIDAPress. Florence, Italy.

Volk, R., Stengel, J., \& Schultmann, F. (2014). Building information modeling (BIM) for existing buildings - Literature review and future needs. In Automation in Construction, Elsevier, 38, 109-127. 